Supplementary information for:

\title{
Structure, Magnetism, and the Interaction of Water with Ti-Doped $\mathrm{Fe}_{3} \mathrm{O}_{4}$ Surfaces
}

Kelsey A. Stoerzinger, ${ }^{1,2^{*}}$ Carolyn I. Pearce, ${ }^{3}$ Timothy C. Droubay, ${ }^{1}$ Vaithiyalingam Shutthanandan, ${ }^{4}$ Zhi Liu, ${ }^{5, \dagger}$ Elke Arenholz, ${ }^{5, \ddagger}$ Kevin M. Rosso, ${ }^{1, *}$

${ }^{1}$ Physical and Computational Sciences Directorate, Pacific Northwest National Laboratory, 902 Battelle Blvd, Richland, WA 99352 USA

${ }^{2}$ School of Chemical, Biological and Environmental Engineering, Oregon State University, 105 SW 26 $6^{\text {th }}$ St \#116, Corvallis, Oregon 97331, USA

${ }^{3}$ Energy and Environment Directorate, Pacific Northwest National Laboratory, 902 Battelle Blvd, Richland, WA 99352 USA

${ }^{4}$ Environmental Molecular Sciences Laboratory, Pacific Northwest National Laboratory, 3335 Innovation Blvd, Richland, WA 99352 USA

${ }^{5}$ Advanced Light Source, Lawrence Berkeley National Laboratory, 6 Cyclotron Rd, Berkeley, CA 94720 USA

${ }^{\dagger}$ Present address: State Key Laboratory of Functional Materials for Informatics, Shanghai Institute of Microsystem and Information Technology, Chinese Academy of Sciences, 865 Changning Road, Shanghai 200050, People's Republic of China; School of Physical Science and Technology, ShanghaiTech University, Shanghai 200031, China

₹Present address: Cornell High Energy Synchrotron Source, 161 Wilson Laboratory, Synchrotron Drive, Ithaca, NY 14853 USA

*Email: kelsey.stoerzinger@pnnl.gov; Kevin.Rosso@pnnl.gov

Figure $\mathrm{S} 1 \ldots \ldots \ldots \ldots \ldots \ldots \ldots \ldots . . . . . \ldots 2$

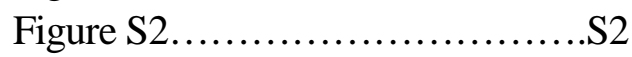

Figure S3........................S3

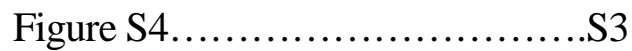

Figure $S 5 . \ldots \ldots \ldots \ldots \ldots \ldots \ldots . . . . . . . . \ldots \ldots$

Figure S6........................S5

Figure $57 \ldots \ldots \ldots \ldots \ldots \ldots \ldots \ldots . . . . . . \ldots 6$

Figure S8.......................S7

Table S1.........................S7

Table S2.........................S8

Table S3..........................S8

Table S4. ...........................S8

Table S5.........................S9

Table S6.........................S9

Table S7..........................S9

Table S8.........................S9 

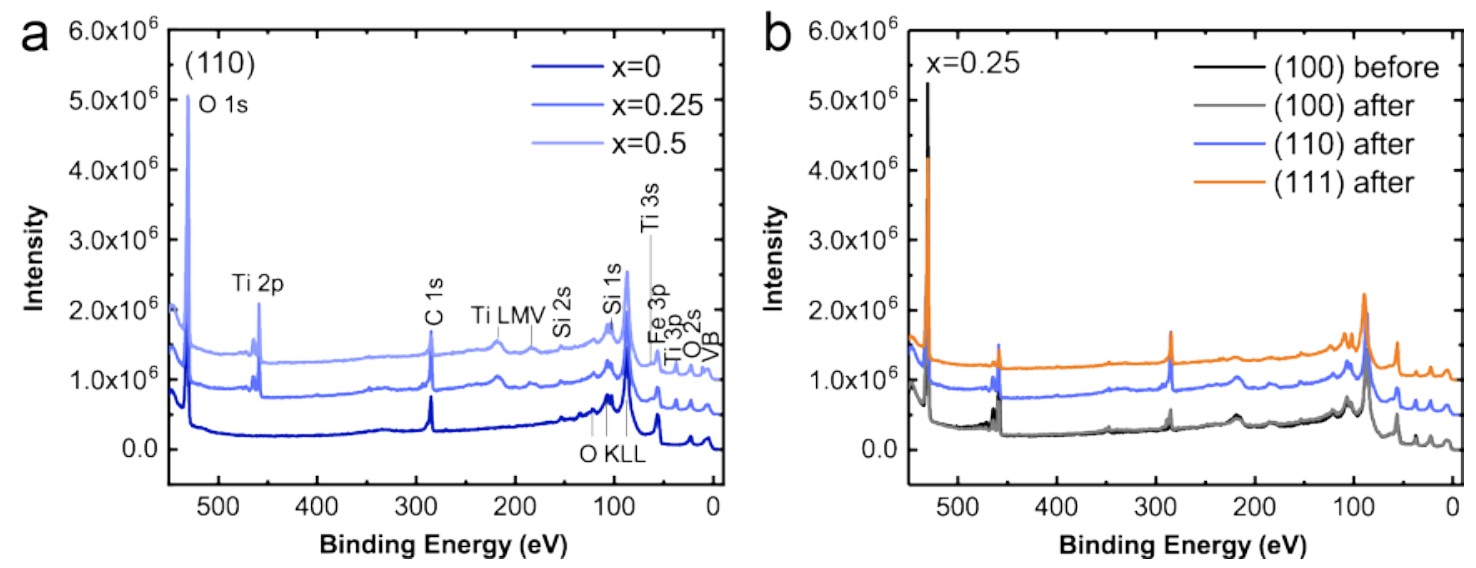

Figure S1. (a) Survey spectra taken after the water isobar for the (110) orientation of the noted composition. (b) Survey spectra taken before (black) and after (gray) the water isobar do not indicate any change in materials stoichiometry or spurious elements, except for some $\mathrm{C}$ and $\mathrm{Si}$ which remain similar over the course of experiments, as shown for $x=0.25$ in the (100) orientation.
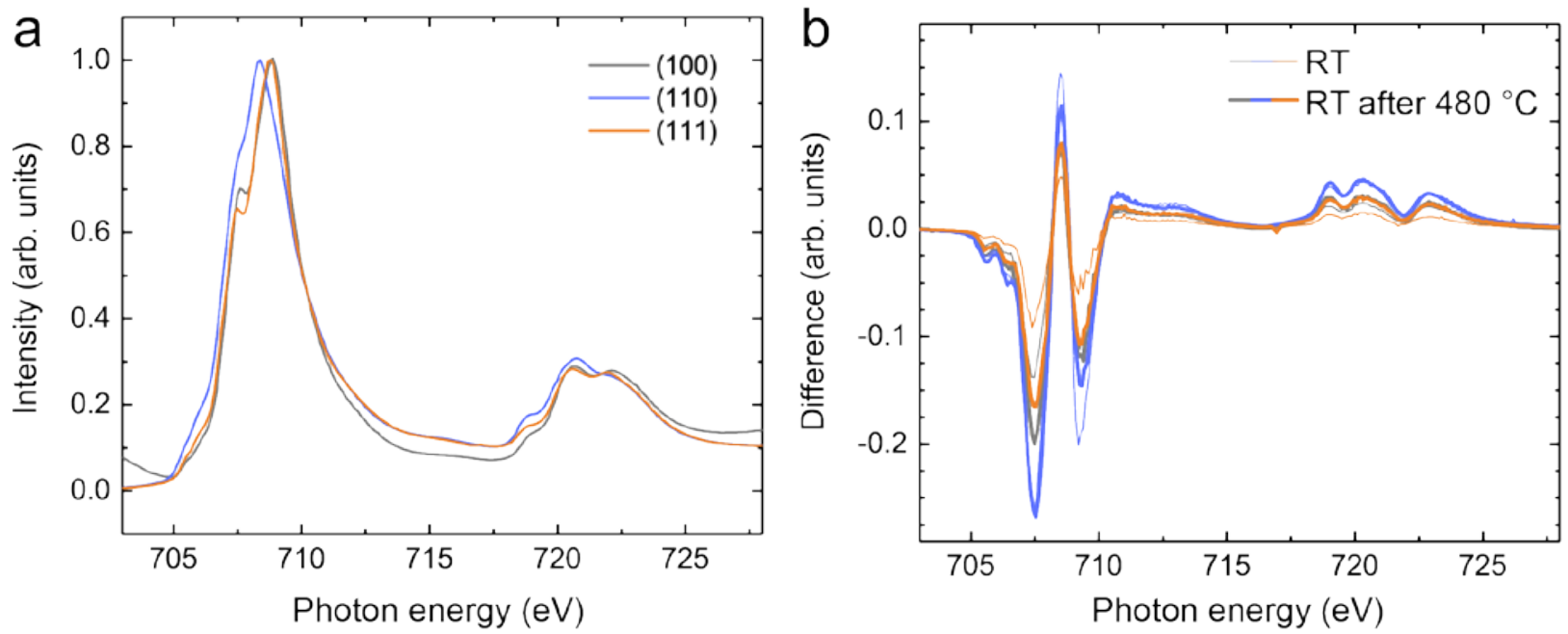

Figure S2. Effect of heating on $x=0$. (a) Fe L-edge XAS measured at RT after heating. (b) XMCD at RT on the as-prepared film (thin, as shown in the main text) compared to at RT after annealing at $\sim 480{ }^{\circ} \mathrm{C}$ for 1 hour (thick). The colors in (b) represent the same orientations as that in (a). 


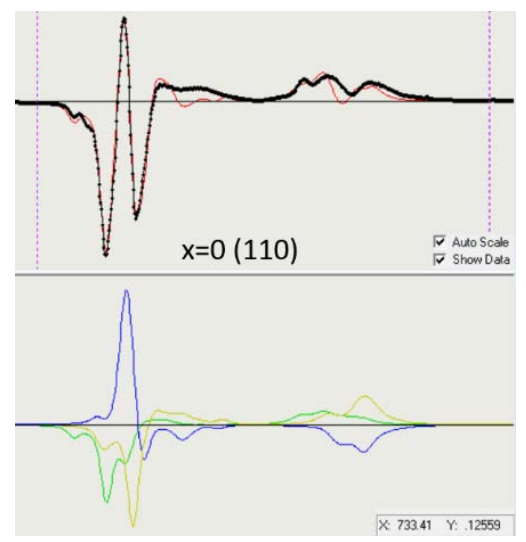

Figure S3. Fe L-edge XMCD at RT in vacuum on as-prepared $\mathrm{Fe}_{3-\mathrm{x}} \mathrm{Ti}_{\mathrm{x}} \mathrm{O}_{4}$ (110) film of composition $\mathrm{x}=0$ showing component spectra for $\mathrm{d} 6 \mathrm{Oh}$ (green), $\mathrm{d} 5 \mathrm{Td}$ (blue) and $\mathrm{d} 5 \mathrm{Oh}$ (yellow) used to generate the fit (red) of the XMCD data (black).

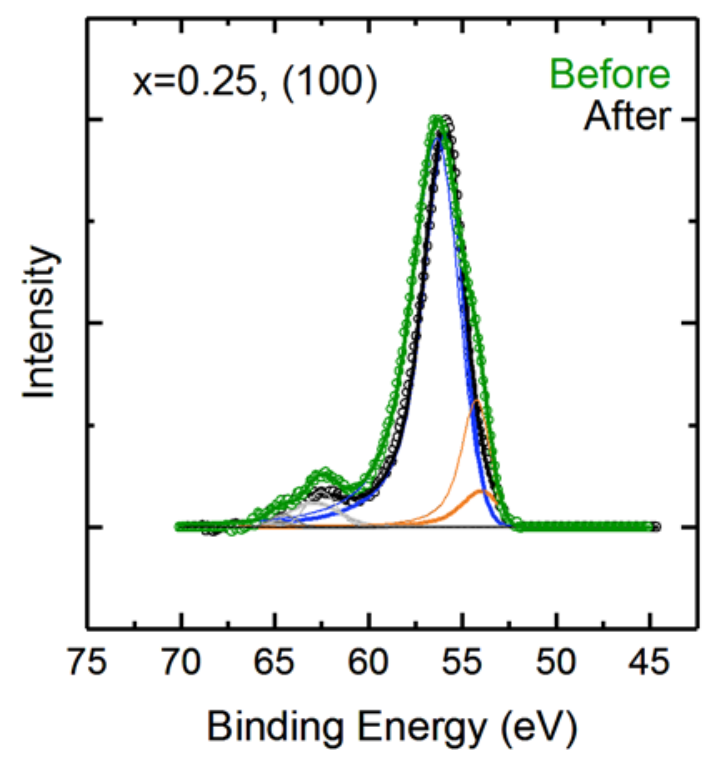

Figure S4. Fe 3p of $x=0.25$ in the (100) orientation, probed in UHV at $\sim 480{ }^{\circ} \mathrm{C}$ before (green envelope, thin components) and after (black envelope, thick components) the water isobar. The satellites (light gray) overlap with the $\mathrm{Ti} 3 \mathrm{~s}$ at $\sim 62 \mathrm{eV}$, but are not expected to impact the $\mathrm{Fe}^{2+}$ (orange): $\mathrm{Fe}^{3+}$ (blue) ratio. Spectra are calibrated to the adventitious carbon binding energy (284.8 $\mathrm{eV}$ ), Shirley-background subtracted and normalized to the maximum intensity. 

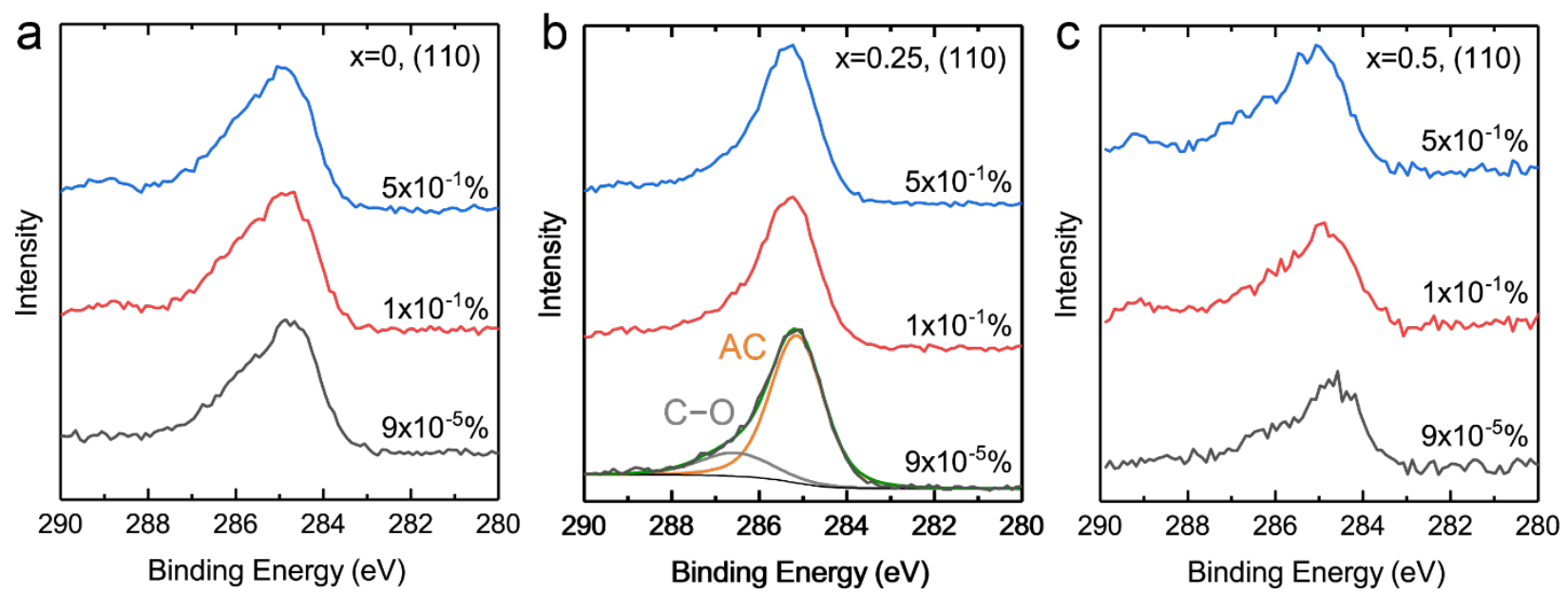

Fig S5. C 1s spectra corresponding to the O 1s spectra in Fig. 5 of the main text at the noted RH. The BE scale was calibrated using the $\mathrm{O} 1 \mathrm{~s}$ as an internal reference, matching that at the lowest $\mathrm{RH}$ to that in UHV after the isobar. The general features remain unchanged in the $\mathrm{C} 1 \mathrm{~s}$, aside from a small increase in oxidized carbon species at $\sim 289 \mathrm{eV}$. Some initial C--O species ${ }^{1}$ are present, but remain comparable in raw intensity throughout the isobar. This is consistent with the small increase in $\mathrm{CO}_{\mathrm{x}}$ species in the $\mathrm{O} 1 \mathrm{~s} 2.35 \mathrm{eV}$ higher in $\mathrm{BE}$ relative to the bulk, where intensity is normalized to the bulk Ox peak in Fig. 5. The intensity ratio of this species in the $\mathrm{O} 1 \mathrm{~s}$ to that in the $\mathrm{C} 1 \mathrm{~s}$ for $\mathrm{x}=0.25$ (110) at $9 \mathrm{x} 10^{-5} \% \mathrm{RH}$ is $\sim 2$, consistent with the relative sensitivity of O:C at similar incident photon energies on the same beamline. 

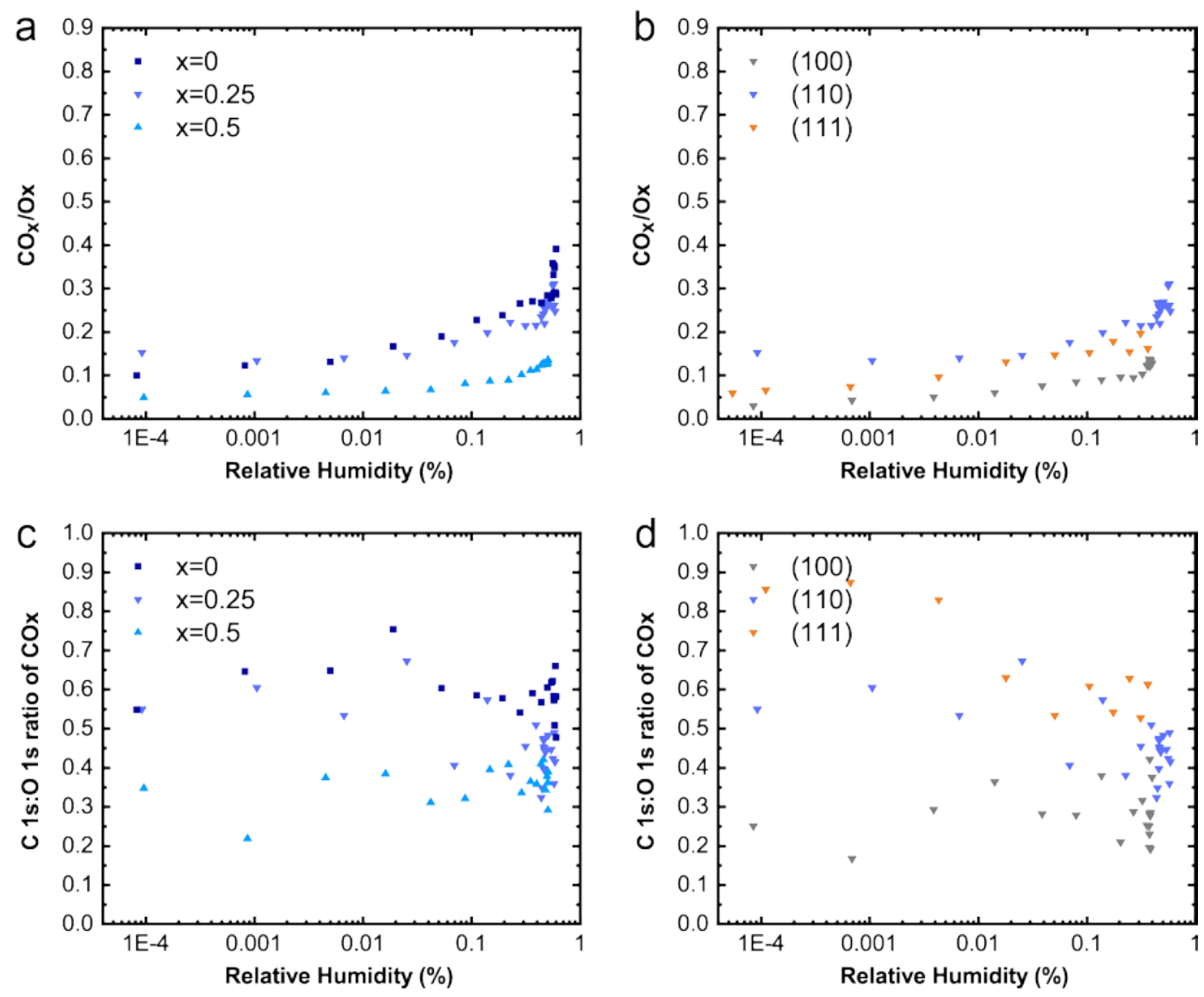

Figure S6. (a, b) Ratio of the $\mathrm{CO}_{\mathrm{x}}$ component relative to the lattice oxide (Ox) intensity, which is proportional to coverage. (b, d) Ratio of the oxidized carbon component in the $\mathrm{C} 1 \mathrm{~s}$ to the $\mathrm{CO}_{\mathrm{x}}$ feature of the $\mathrm{O} 1 \mathrm{~s}$, which is similar across compositions and relative humidity. Compared in (a, c) are noted compositions in the (110) orientation, and (b, d) noted orientations at the $\mathrm{x}=0.25$ composition. 

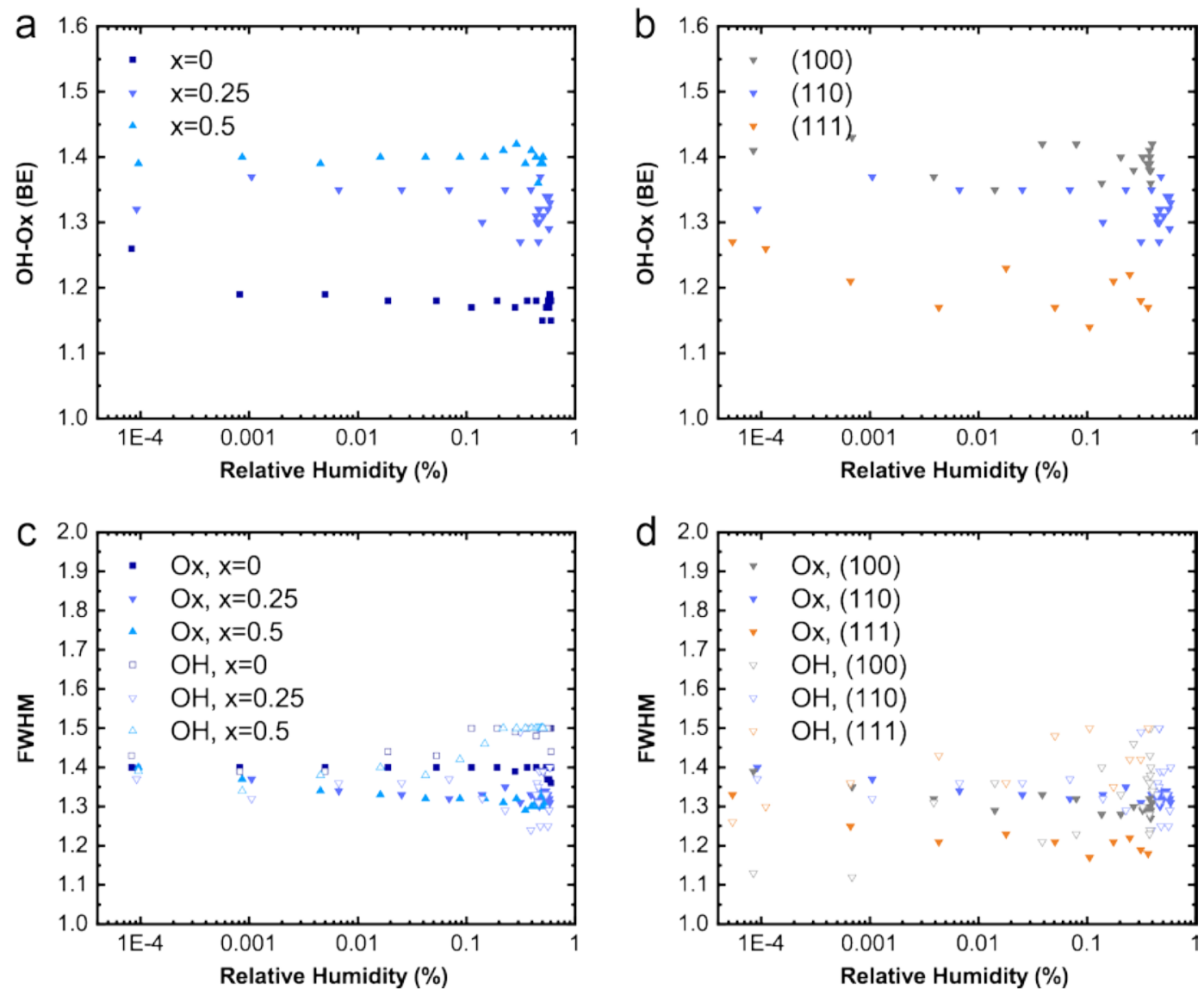

Figure S7. (a, b) Binding energy (BE) location of the Ox feature relative to the bulk $\mathrm{OH} \mathrm{BE}$ as a function of relative humidity. The smaller BE offset for the $x=0$ (110) and $x=0.25$ (111) film are required for a good fit to the spectra, and are correlated with these surfaces having the highest $\mathrm{OH} / \mathrm{Ox}$ ratio. However, fixing the $\mathrm{BE}$ offset to $1.4 \mathrm{eV}$ does not change the trends in $\mathrm{OH} / \mathrm{Ox}$ ratio, only the absolute magnitude. (c, d) FWHM of the Ox feature (closed) and OH feature (open). Similar to other reports, the Ox feature decreases in FWHM with $\mathrm{RH}^{1-2}$ The OH FWHM is generally larger and similar across RH. Compared in (a, c) are noted compositions in the (110) orientation, and $(\mathrm{b}, \mathrm{d})$ noted orientations at the $\mathrm{x}=0.25$ composition. 

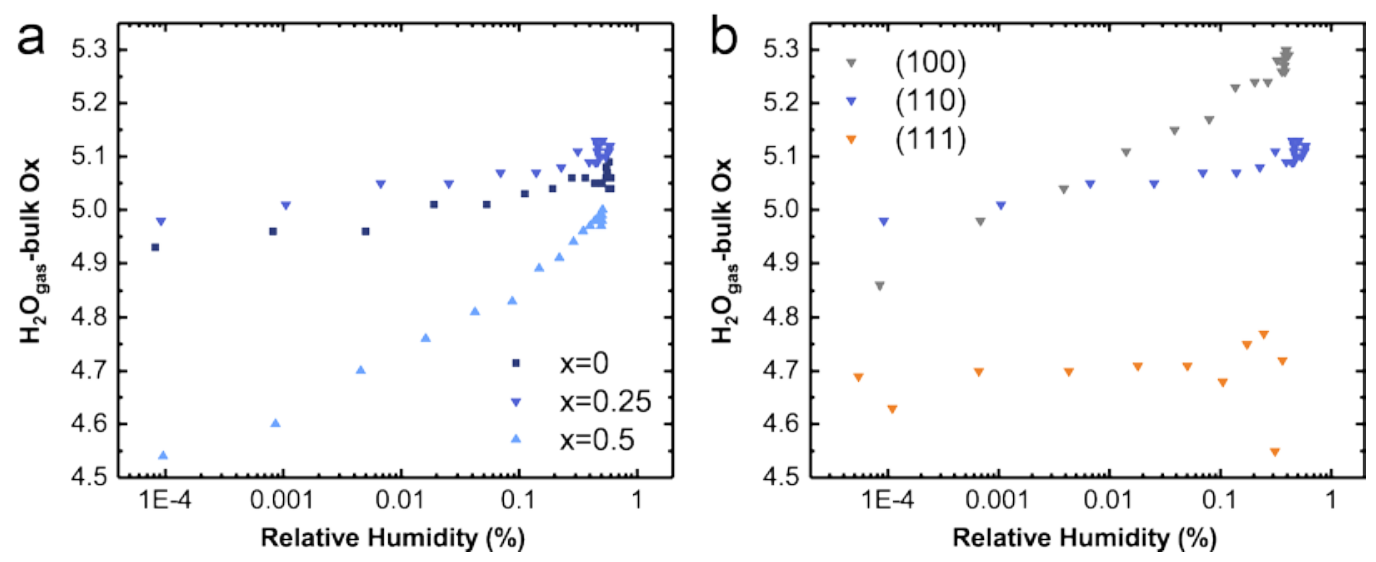

Figure S8. The difference in the $\mathrm{H}_{2} \mathrm{O}_{\text {gas }}$ peak BE relative to that of the bulk oxide for (a) different compositions in the (110) orientation and (b) different orientations for $x=0.25$. The increase in relative gas phase $\mathrm{BE}$ is indicative of a decrease in surface work function or change in surface dipole facilitating the removal of photoelectrons from the surface. The sample was not approached or retracted relative to the analyzer or X-ray beam during measurement of the isobar.

Table S1. Atomic concentration from RBS in $\mathrm{Fe}_{(3-\mathrm{x})} \mathrm{Ti}_{\mathrm{x}} \mathrm{O}_{4}$, modeling the top $5 \mathrm{~nm}$ as the "surface". Using XPS, the Fe/Ti ratio is estimated after the water isobar, measured in UHV. Intensities of the Fe 3p and Ti 2p are corrected by tabulated cross sections, ${ }^{3}$ an estimate of the different photon fluxes comparing the $\mathrm{C} 1 \mathrm{~s}$ at both IPEs, the estimated difference in spectrometer efficiencies at the two KEs obtained by comparing the $\mathrm{O} 1 \mathrm{~s}$ (KE of $~ 70 \mathrm{eV}$ at an IPE of $600 \mathrm{eV}$ ) and $\mathrm{O}$ 2s (KE of $\sim 470 \mathrm{eV}$ at an IPE of $490 \mathrm{eV}$ ) corrected by the flux and cross section, and the IMFPs calculated for $\mathrm{Fe}_{3} \mathrm{O}_{4}$. Note that the IMFP correction assumes the film composition is uniform (taking into account the ratio of over which 95\% of the signal was collected), although RBS and previous depth profiling for the (100) orientation in ref. ${ }^{4}$ indicates $\mathrm{Ti}$ is enriched at the surface. This enrichment would result in the Fe/Ti ratio being lower than expected, as observed.

\begin{tabular}{l|cc|cc|c} 
& \multicolumn{2}{|c|}{ Bulk RBS } & \multicolumn{2}{c|}{ Surface RBS } & XPS \\
\hline & $\mathrm{x}$ & $\mathrm{Fe} /$ Ti ratio & $\mathrm{x}$ & $\mathrm{Fe} / \mathrm{Ti}$ ratio & $\mathrm{Fe} / \mathrm{Ti}$ ratio* \\
\hline $\mathrm{x}=0(110)$ & 0.02 & 143.33 & 0.01 & 225.00 & - \\
$\mathrm{x}=0.25(110)$ & 0.25 & 11.14 & 0.48 & 5.21 & $1.51 \pm 0.22$ \\
$\mathrm{x}=0.5(110)$ & 0.42 & 6.18 & 0.69 & 3.32 & $1.43 \pm 0.21$ \\
\hline
\end{tabular}

* Corrected by the difference in flux for the two IPEs, the estimated difference in spectrometer efficiencies at the two KEs, the cross section at the IPE of $490 \mathrm{eV}$ for the Fe 3p and $600 \mathrm{eV}$ for the $\mathrm{Ti} 2 \mathrm{p},{ }^{3}$ and the difference in depth leading to $95 \%$ of the signal, as obtained from the IMFP calculated for $\mathrm{Fe}_{3} \mathrm{O}_{4}{ }^{5-6}$ 
Table S2. Ratio of $\mathrm{Fe}^{2+}$ to $\mathrm{Fe}^{3+}$ by XMCD at the Fe L-edge, collected in TEY mode at RT in UHV.

\begin{tabular}{|l|c|c|} 
& \multicolumn{2}{|c|}{$\mathbf{F e}^{2+} / \mathbf{F}^{3+}$} \\
& Before Heating & After Heating @ 750K \\
\hline$x=0.00(100)$ & 0.523 & 0.724 \\
$x=0.00(110)$ & 0.541 & 0.744 \\
$x=0.00(111)$ & 0.599 & 0.661 \\
\hline$x=0.25(100)$ & 0.483 & - \\
$x=0.25(110)$ & 0.590 & - \\
$x=0.25(111)$ & 0.299 & - \\
& & - \\
\hline$x=0.50(100)$ & 0.378 & - \\
$x=0.50(110)$ & 0.613 & - \\
$x=0.50(111)$ & 0.128 & \\
\hline
\end{tabular}

Table S3. Percent contribution of the $\mathrm{Fe} 3 p$ signal by $\mathrm{Fe}^{2+}$ (relative to $\mathrm{Fe}^{2+}$ and $\mathrm{Fe}^{3+}$ combined) and the \%Ti from the core level ratio Ti $2 p /(\operatorname{Ti} 2 p+F e 3 p)$ for $x=0.25$. The satellite features in the Fe 3p, which are negligible and overlap with the Ti 3s, are not included in either calculation. The (110) orientation generally has a higher amount of $\mathrm{Fe}^{2+}$ and $\mathrm{Ti}$. "Before" the isobar is at $\sim 480{ }^{\circ} \mathrm{C}$ in UHV, while "After" the isobar is at RT in UHV.

\begin{tabular}{|l|c|c|c|c|}
\hline & \multicolumn{2}{|c|}{$\% \mathrm{Fe}^{2+}$ (3p) } & \multicolumn{2}{c|}{$\% \mathrm{Ti}$} \\
\hline & Before & After & Before & After \\
\hline $\mathrm{x}=0.25(100)$ & 16 & 4 & 65 & 44 \\
\hline $\mathrm{x}=0.25(110)$ & 33 & 31 & 67 & 62 \\
\hline $\mathrm{x}=0.25(111)$ & 8 & 1 & 33 & 32 \\
\hline
\end{tabular}

Table S4. Percent contribution of the Fe 3p signal by $\mathrm{Fe}^{2+}$ (relative to $\mathrm{Fe}^{2+}$ and $\mathrm{Fe}^{3+}$ combined) for the (110) orientation. The satellite features in the Fe 3p, which are negligible and overlap with the Ti 3s, are not included in either calculation. "Before" the isobar is at $\sim 480{ }^{\circ} \mathrm{C}$ in UHV.

\begin{tabular}{|l|c|}
\hline \multicolumn{1}{|c|}{} & Before \\
\hline $\mathrm{x}=0.0(110)$ & 23 \\
\hline $\mathrm{x}=0.25(110)$ & 33 \\
\hline $\mathrm{x}=0.5(110)$ & 30 \\
\hline
\end{tabular}


Table S5. Fe 3p fitting in CasaXPS. Similar $\mathrm{Fe}^{2+}: \mathrm{Fe}^{3+}$ ratios were obtained with a symmetric peak fitting as well. The satellites overlap with the Ti 3s at $\sim 62 \mathrm{eV}$, but are not expected to impact the $\mathrm{Fe}^{2+}: \mathrm{Fe}^{3+}$ ratio.

\begin{tabular}{l|cccc}
\hline & $\mathrm{Fe}^{3+}$ & $\mathrm{Fe}^{2+}$ & Satellite 1 & Satellite 2 \\
\hline Line shape & $\mathrm{A}(0.35,0.4,0) \mathrm{GL}(0)$ & $\mathrm{A}(0.35,0.4,0) \mathrm{GL}(0)$ & $\mathrm{GL}(0)$ & $\mathrm{GL}(0)$ \\
FWHM & $0.52,3$ & $0.52,3$ & $0.52,3.5$ & $0.52,3.5$ \\
Binding energy & $>52$ & $54,54.5$ & $>60$ & $>62$ \\
\hline
\end{tabular}

Table S6. Fitting parameters for the O 1s spectra in CasaXPS, using a Gaussian line shape.

\begin{tabular}{l|ccccc}
\hline & $\mathrm{Ox}$ & $\mathrm{OH}$ & $\mathrm{CO}_{\mathrm{x}}$ & $\mathrm{H}_{2} \mathrm{O}_{\text {ads }}$ & $\mathrm{H}_{2} \mathrm{O}_{\text {gas }}$ \\
\hline FWHM & $<1.4$ & $<1.5^{\wedge}$ & $<2$ & $<2$ & $<1.2$ \\
Location & Free & $\mathrm{Ox}+1.15-1.5$ & $\mathrm{Ox}+2.35$ & $\mathrm{Ox}+3.3^{*}$ & $>534$ \\
\hline
\end{tabular}

$\wedge$ The FWHM was constrained only to be less than 1.5, but the fitted values ranged from 1.25-1.5. *Location on an absolute energy scale is $~ 534 \mathrm{eV}$, similar to other reports in literature. ${ }^{2,4,7-8}$

Table S7. Change in surface speciation and valence for $\mathrm{x}=0.25$ films in the noted orientation. Given is the difference in $\mathrm{OH}(\Delta \mathrm{OH})$ and the ratio of $\mathrm{Fe}^{2+} /\left(\mathrm{Fe}^{2+}+\mathrm{Fe}^{3+}\right)$ from the Fe 3p spectrum $\left(\Delta \mathrm{Fe}^{2+}\right)$ measured in UHV before (hot) and after (RT).

\begin{tabular}{|c|c|c|}
\hline & $\Delta \mathrm{OH}$ & $\Delta \mathrm{Fe}^{2+}$ \\
\hline $\mathrm{x}=0.25(100)$ & 0.26 & 0.13 \\
\hline $\mathrm{x}=0.25(110)$ & 0.13 & 0.02 \\
\hline $\mathrm{x}=0.25(111)$ & 0.09 & 0.08 \\
\hline
\end{tabular}

Table S8. Change in surface speciation and valence for films in the (110) orientation. Given is the difference in $\mathrm{OH}(\Delta \mathrm{OH})$ and the ratio of $\mathrm{Fe}^{2+} /\left(\mathrm{Fe}^{2+}+\mathrm{Fe}^{3+}\right)$ from the $\mathrm{Fe} 3 p$ spectrum $\left(\Delta \mathrm{Fe}^{2+}\right)$ measured in UHV before (hot) and after (RT).

\begin{tabular}{|l|c|c|}
\hline & $\Delta \mathrm{OH}$ & $\Delta \mathrm{Fe}^{2+}$ \\
\hline $\mathrm{x}=0(110)$ & 0.49 & 0.03 \\
\hline $\mathrm{x}=0.25(110)$ & 0.13 & 0.02 \\
\hline $\mathrm{x}=0.5(110)$ & 0.14 & 0.09 \\
\hline
\end{tabular}

\section{Supplementary References:}

1. Yamamoto, S.; Kendelewicz, T.; Newberg, J. T.; Ketteler, G.; Starr, D. E.; Mysak, E. R.; Andersson, K. J.; Ogasawara, H.; Bluhm, H.; Salmeron, M.; Brown, G. E.; Nilsson, A., Water Adsorption on $\alpha-\mathrm{Fe}_{2} \mathrm{O}_{3}(0001)$ at near Ambient Conditions. The Journal of Physical Chemistry C 2010, 114 (5), 22562266.

2. $\quad$ Kendelewicz, T.; Kaya, S.; Newberg, J. T.; Bluhm, H.; Mulakaluri, N.; Moritz, W.; Scheffler, M.; Nilsson, A.; Pentcheva, R.; Brown, G. E., X-ray Photoemission and Density Functional Theory Study of 
the Interaction of Water Vapor with the $\mathrm{Fe}_{3} \mathrm{O}_{4}(001)$ Surface at Near-Ambient Conditions. The Journal of Physical Chemistry C 2013, 117 (6), 2719-2733.

3. Yeh, J. J., Atomic Calculation of Photoionization Cross-Sections and Asymmetry Parameters. Gordon and Breach Science Publishers: Langhorne, PE (USA), 1993.

4. $\quad$ Stoerzinger, K. A.; Pearce, C. I.; Droubay, T. C.; Shutthanandan, V.; Shavorskiy, A.; Bluhm, H.; Rosso, K. M., Impact of Ti Incorporation on Hydroxylation and Wetting of $\mathrm{Fe}_{3} \mathrm{O}_{4}$. The Journal of Physical Chemistry C 2017, 121 (35), 19288-19295.

5. $\quad$ Powell, C. J.; Jablonski, A., NIST Electron Inelastic-Mean-Free-Path Database - Version 1.2. National Institute of Standards and Technology: Gaithersburg, MD, 2010.

6. $\quad$ S., T.; J., P. C.; R., P. D., Calculations of electron inelastic mean free paths. V. Data for 14 organic compounds over the 50-2000 eV range. Surface and Interface Analysis 1994, 21 (3), 165-176. 7. Henderson, M. A., The interaction of water with solid surfaces: fundamental aspects revisited. Surface Science Reports 2002, 46 (1), 1-308.

8. $\quad$ Stoerzinger, K. A.; Hong, W. T.; Crumlin, E. J.; Bluhm, H.; Biegalski, M. D.; Shao-Horn, Y., Water Reactivity on the $\mathrm{LaCoO}_{3}$ (001) Surface: An Ambient Pressure X-ray Photoelectron Spectroscopy Study. The Journal of Physical Chemistry C 2014, 118 (34), 19733-19741. 